\title{
Mensenrechten en democratie als graadmeter voor het punitieve klimaat in een land
}

\author{
Miranda Boone \\ Hoogleraar, Instituut voor Strafrecht \& Criminologie, Universiteit Leiden
}

Hoewel Sonja Snacken en ik niet veel direct hebben samengewerkt, ben ik haar gedurende mijn hele loopbaan met grote regelmaat tegengekomen op congressen en andere gelegenheden. Dat is niet gek, want we bewegen ons beiden op het raakvlak van recht en criminologie en ik ben altijd een groot bewonderaar geweest van haar werk. Ze heeft onnoemelijk veel penologische thema's op de kaart gezet of nieuw leven ingeblazen, van welke uiteenzettingen ik ook in mijn werk gretig gebruik heb gemaakt. In deze korte bijdrage voor haar liber amicorum wil ik een van die verdiensten belichten, namelijk de introductie van het mensenrechtendiscours in het debat over ontwikkelingen in punitiviteit.

Punitiviteit is een omstreden begrip dat alleen onder penologen met grote vanzelfsprekendheid wordt gebruikt. Omdat ik in dit artikel geen ruimte heb om diep op al die betekenissen in te gaan, beroep ik me voor het gemak op een beschrijving die Sonja zelf in een van haar publicaties gaf:

\footnotetext{
'Punitiveness' thus has a quantitative and a qualitative dimension, which goes beyond the often used prison population rates per 100,000 inhabitants. It is a complex, not always clearly defined concept. It refers in general to 'attitudes towards punishment', including, but not limited to: political discourse; primary criminalization by legislators; decisions taken by practitioners within the criminal justice system (police, prosecution, sentencing, implementation of sentences, release procedures, etc.); attitudes of revenge or forgiveness of victims of crime; or 'popular' attitudes towards punishment. (Snacken, 2010: 274)
} 
Fluctuaties en verschillen in punitiviteit zijn een belangrijk onderzoeksthema binnen de penologie. In het algemeen wordt aangenomen dat veranderingen in punitiviteit, maar in geringe mate samenhangen met veranderingen in het niveau van criminaliteit en daarom aanleiding zijn voor veel breder onderzoek naar veranderingen die zich hebben voorgedaan in het strafrechtsysteem en daarbuiten (Snacken Beyens \& Tubex, 1995; Von Hofer, 2003; Pfaff, 2008). Met name de wereldwijde toename van het aantal gedetineerden in de laatste decennia van de vorige eeuw heeft geleid tot een levendige theorievorming en conceptualisering om die ontwikkeling te duiden. Hardere en meer uitsluitende straffen of maatregelen werden door verschillende theoretici in verband gebracht met een aantal ingrijpende wijzigingen die zich in de samenleving hebben voorgedaan. Sociologen als Ulrich Beck, Jock Young en David Garland hebben die veranderingen in aanstekelijke bewoordingen geschetst. Het gemeenschappelijke punt in hun verklaringen is dat de grote veranderingen die de moderne samenleving met zich brengt, de voortdurende beweging, vloeibaarheid heeft Bauman het genoemd (Bauman, 2000), en de ongrijpbaarheid van de risico's die daarmee samengaan, de burger onzeker maken en doet vastklampen aan datgene wat vertrouwd is. Wat vreemd is of een potentieel risico inhoudt, wordt afgewezen. Bovengenoemde auteurs spreken daarom wel afwisselend van een risicosamenleving (Beck, 1992; Hudson, 2003), een exclusive society (Young, 1999), een controlecultuur (Garland, 2001) of een zondeboksamenleving (Young, 1999; Beck, 1992). Dergelijke concepten helpen je nieuwe richtingen en ontwikkelingen in de samenleving te duiden en te begrijpen en zijn in die zin erg waardevol. Maar ze bergen ook het gevaar van een wetenschappelijke tunnelvisie, waarin nieuwe verschijnselen kritiekloos als een bevestiging worden gezien van de bestaande theorieën.

Het is een van de verdiensten van Sonja Snacken geweest dat zij zich in verschillende publicaties heeft verzet tegen het té eenduidig toepassen van deze theorieën en concepten (Snacken, 2006; Snacken, 2010; Snacken, 2015). Zij laat zien dat er, in ieder geval in Europa, ook sprake is van een tegengestelde tendens die vooral wordt veroorzaakt door de invloed van het mensenrechtelijke discours. Ze wijst op de afschaffing van de doodstraf op het hele Europese continent, op de introductie van niet-vrijheidsberovende sancties in alle Oost-Europese landen en op een herleving van het resocialisatieideaal op basis van de principes van What Works. Zij wijst erop dat de gemiddelde detentieratio ook in Europa weliswaar aanzienlijk is gestegen, maar dat er eveneens grote verschillen zijn tussen landen. Bovenal zijn de rechten van gedetineerden aanzienlijk versterkt door de actieve rol van het 
anti-foltercomité van de Raad van Europa en de jurisprudentie van het Europese Hof voor de Rechten van de Mens (Snacken, 2006; 2010).

Snacken zelf gebruikt die constatering om te pleiten voor het inzetten van mensenrechten in een reductionistische strafrechtelijke politiek (Rutherford, 1984; Snacken, 2010). Zelf ben ik er in de loop van de tijd minder van overtuigd geraakt dat het louter inzetten van juridische instrumenten sociale verandering in gang kan zetten, maar ik ben wel zeer geïnteresseerd in internationaal comparatief onderzoek naar de condities waaronder recht verandering teweeg kan brengen. Haar constatering geeft bovenal aanleiding tot meer precieze empirische analyses van verschijnselen in het licht van de macro-sociologische theorieën die ik zojuist heb genoemd. Niet iedere aanscherping van het strafrechtelijke beleid is een bevestiging van het punitieve klimaat van een land. Men kan verschillende criteria aanleggen om tot een dergelijke beoordeling te komen. Bijvoorbeeld of de maatregel proportioneel is aan het verschijnsel dat het wil bestrijden, of het daartoe op zichzelf een geëigend (effectief) middel is en of er juridische instrumenten tegen kunnen worden aangewend en worden aangewend die het punitieve tij weer kunnen keren. Ik geef twee voorbeelden.

Het eerste voorbeeld is al enigszins gedateerd en betreft de introductie van de zogenaamde terroristenafdeling in het Nederlandse gevangeniswezen, een afdeling waarin substantieel wordt afgeweken van normale rechten van gedetineerden, en die bedoeld is om het ronselen en rekruteren van andere gedetineerden voor het terroristische gedachtegoed tegen te gaan (Boone, 2009; Veldhuizen et al, 2010; Bovenkerk, 2011). Ik heb me destijds naar aanleiding van Sonja's publicaties afgevraagd of deze als een typisch product van de Nederlandse zondeboksamenleving moet worden gezien of dat de wijze waarop deze zich heeft ontwikkeld juist laat zien dat ook de welzijnsbenadering en het human rights discours (nog) springlevend zijn. ${ }^{2}$

Het zondebokmechanisme is volgens Ulrich Beck een typisch kenmerk van een risicosamenleving:

The risk society contains an inherent tendency to become a scapegoat society: suddenly it is not the hazards, but those who point them out that provoke the general uneasiness (...). Is it not spies, communists, Jews, Turks or asylum seekers from the Third World who are ultimately behind it. (Beck, 1992: 75)

2 Ik heb voor het begrip zondeboksamenleving gekozen, omdat het (iets) meer concreet en toetsbaar is dan een van de andere genoemde begrippen (exclusive society, risk society), maar had die begrippen er in principe voor in de plaats kunnen stellen. 
In Garlands 'culture of control' komen zondebokken terug als 'dangerous others' who 'threaten our safety and have no calls on our fellow feeling.' (Garland, 2001: 184).

Dit intrinsieke anders zijn rechtvaardigt ook een andere behandeling. Zondebokken zijn personen of eigenlijk groepen van personen die als een zodanige bedreiging voor de stabiliteit en het welzijn van de samenleving worden beschouwd dat ze als het ware buiten de normale rechtsorde worden geplaatst. Dat is het centrale aspect. Omdat het zondebokken zijn, 'dangerous' of zelfs 'monstrous others', kunnen ze ook geen aanspraak meer maken op de rechtsbescherming en vrijheidsrechten die de rechtstaat normaliter biedt. Barbara Hudson heeft hier wat mij betreft nog het meest indringend over geschreven.

The 'monstrous others' challenge the limits of the traditional, liberal and communitarian, notions of justice. Contemporary societies face the challenge of dealing with people who are so different that they really seem to be beyond inclusion in the liberal community. (Hudson 2003: 290)

Afgaande op deze beschrijvingen is het verleidelijk de introductie van de terroristenafdeling af te doen als een punitieve maatregel die naadloos aansluit bij het concept zondeboksamenleving. Er waren ook zeker argumenten die pleiten voor een dergelijke constatering (Boone, 2009). De inzet van het middel was destijds weliswaar begrijpelijk in het licht van de gevaren die Nederland leken te bedreigen, maar de wijze waarop het werd toegepast was niet proportioneel en zeker niet bewezen effectief. Integendeel, uit de bestaande literatuur bleek juist dat het heel goed contraproductief zou kunnen zijn (Boone, 2009). Het punt dat ik nu wil maken, is echter dat het verzet dat deze maatregel heeft opgeroepen in verschillende segmenten van de Nederlandse samenleving en de juridische maatregelen die er destijds (effectief) tegen zijn aangewend, juist ook wijzen op sterke krachten die zich keren tegen een zondeboksamenleving.

De Raad voor Strafrechtstoepassing en Jeugdbescherming (RSJ), een onafhankelijk adviesorgaan van de regering en tevens beroepsinstantie voor klachten van gedetineerden, adviseerde uitdrukkelijk het openen van de afdeling achterwege te laten. De belangrijkste bezwaren van de RSJ betroffen de wijze van selectie, het gebrek aan differentiatie en het regime. De RSJ wees een categoraal selectiecriterium af en stelde in zijn advies dat 'in de persoon van de gedetineerde een aanleiding gevonden zal moeten worden om aan te nemen dat zijn radicale denkbeelden een beheersrisico vormen' (RSJ, 2006:5). In de jurisprudentie die volgde op de inwerkingtreding van de Regeling, 
draaide de beroepscommissie van de RSJ die beoordeling om, maar ging er nog steeds van uit dat gedetineerden alleen op de afdeling konden worden geplaatst 'als er geen bijzondere omstandigheden zijn die tot een ander oordeel dwingen' (Boone, 2009: 50).

In even negatieve bewoordingen liet het Committee for the Prevention of Torture (CPT) van de Raad van Europa die de terroristenafdeling betrekkelijk kort na de opening bezocht zich uit. Ook dit comité verbaasde zich in uitgesproken bewoordingen over het categorale criterium, vooral nu de gedetineerden die ten tijde van hun bezoek op de afdeling verbleven tot hun overplaatsing probleemloos op andere afdelingen hadden verbleven. Al even negatief was het over het regime dat werd gevoerd op 'de terroristenafdeling'. Voor extreem vluchtgevaarlijke gedetineerden, pleitten zij in hun rapporten consequent voor gevangenissen die van buiten weliswaar goed beveiligd zijn, maar van binnen een grote mate van vrijheid toestaan. Dat zou volgens hen ook voor de doelgroep van de terroristenafdeling moeten gelden.

The CPT's position concerning restricted regimes on high-security units is well known to the Netherlands authorities and there has been an extensive exchange of views on this matter in the past. The CPT considers that prisoners, who present a particularly high-security risk should, within the confines of their detention units, enjoy a relatively relaxed regime by way of compensation for their severe custodial situation. In particular, they should be able to meet their fellow prisoners in the unit and be granted a good deal of choice concerning their activities (thus fostering a sense of autonomy and personal responsibility). Special efforts should be made to develop a good atmosphere within high-security units. The aim should be to build positive relations between staff and prisoners. Further, particular attention should be paid to the mental health of prisoners placed in these departments. (CPT 2008, overweging 45)

Niet alleen organen die belast zijn met het toezicht op detentiesituaties, ook een deel van de media heeft de terroristenafdeling kritisch gevolgd. Er zijn diverse televisie-uitzendingen over dit thema gemaakt (Veldhuis et al, 2010: 124), waaronder een kritische documentaire genaamd Guantanamo Vught. Hierin kwamen ex-gedetineerden en familieleden aan het woord die het regime op de afdeling 'inhumaan' en contra-productief noemden, oordelen die werden bevestigd door terrorisme-experts en deskundigen op het gebied van het detentierecht. Ruimschoots aandacht was er ook in de pers voor de hongerstaking van een van de gedetineerden en voor de positie van de enige vrouwelijke gedetineerde die langer op de terroristenafdeling verbleef. Ook 
werden zeer regelmatig Kamervragen over de terroristenafdeling gesteld ${ }^{3}$ en hebben wetenschappers er kritisch over gepubliceerd (Boone, 2009; Bovenkerk, 2011; Veldhuis et al, 2010).

$\mathrm{Al}$ dan niet als gevolg van al deze kritiek, is er in 2009 al sprake geweest van een grondige regimeverbetering. Hierdoor kregen gedetineerden meer bewegingsvrijheid, konden zij meer tijd buiten hun cel doorbrengen en werden zij minder vaak gefouilleerd (Veldhuis et al, 2010: 17). Het aantal gedetineerden dat op een van beide terroristenafdelingen heeft verbleven, is in die periode ook steeds heel klein gebleven, een van de twee afdelingen werd na verloop van tijd zelfs gesloten. De komst van Syrische jihadstrijders heeft ze weer nieuw leven ingeblazen. Vanaf dat moment heb ik de ontwikkeling niet meer gevolgd.

Het tweede voorbeeld is recenter en kent voorlopig geen goede afloop. Het betreft de omgang van Nederland met de levenslange gevangenisstraf, meer concreet voor deze bijdrage: de onlangs genomen beslissing van de Nederlandse minister van Rechtsbescherming om het zesde gratieverzoek van de tot levenslang veroordeelde Chinese gedetineerde Loi $\mathrm{C}$ af te wijzen. ${ }^{4}$ Anders dan België en bijna alle andere Europese landen, kent Nederland geen automatische herzieningsprocedure op basis waarvan na een bepaalde periode wordt gekeken of de levenslange gevangenisstraf nog wel onverkort moet worden ten uitvoer gelegd. De veroordeelde heeft wel de mogelijkheid een gratieverzoek in te dienen, maar het is zeer de vraag of dat voldoet aan de eisen die het EHRM hieraan stelt. Daar lijkt het niet meer op, nu sinds 2004 opeenvolgende ministers en staatssecretarissen hardop uitspraken dat levenslang in Nederland levenslang is en er sinds 1986 ook geen gratieverzoeken meer zijn gehonoreerd. De enige uitzondering hierop is het ingewilligde verzoek van een terminale gedetineerde, die inderdaad kort na zijn invrijheidstelling overleed. Nederlandse juristen zijn dan ook sterk verenigd in hun afwijzing van de huidige regeling van de levenslange gevangenisstraf. De instelling van een Adviescollege levenslang gestraften dat de minister na 25 jaar moet adviseren of een veroordeelde met reïntegratieactiviteiten kan starten, heeft daaraan niets veranderd. ${ }^{5}$

Inmiddels verblijft Loi C 32 jaar in detentie. Ik was in 2014 (!) zelf bij zijn zaak betrokken als lid van de commissie van de Raad voor Strafrechts-

3 Oa Kamerstukken II, 2006/07, Aanhangsel Handelingen nr. 2066; Kamerstukken II, 2007-2008, Aanhangsel Handelingen, 32705, nr. 3017; Kamerstukken II, 2006-2006. Aanhangsel Handelingen 26814, nr. 373.

4 https://www.volkskrant.nl/nieuws-achtergrond/opnieuw-geen-gratie-voor-levenslang-gestrafte-loi-c $\sim$ b0adf $42 \mathrm{c} /$

5 Zie voor alle informatie omtrent de uitvoering van de levenslange straf in Nederland en de kritiek daarop de website van het Forum levenslang. 
toepassing en Jeugdbescherming die in hoger beroep oordeelt over verloven van gedetineerden. Waar dergelijke beslissingen meestal schriftelijk en een enkele keer in zeer besloten kring worden genomen, weet ik nog dat ik destijds zeer onder de indruk was van de afvaardiging vanuit het ministerie van Justitie die op deze zitting aanwezig was. De toekenning van het begeleid verlof was destijds een eerste stapje op weg naar de voorbereiding van de reintegratie van Loi $\mathrm{C}^{6}$ en een noodzakelijke voorwaarde voor het toekennen van gratie. Sinds die tijd heeft deze veroordeelde iedere verdere stap voor de rechter moeten afdwingen. Na vijf jaar lag er eindelijk een positief advies van het gerechtshof dat oordeelde 'dat met de tenuitvoerlegging van de rechterlijke beslissing of voortzetting daarvan geen met de strafrechtstoepassing na te streven doel in redelijkheid wordt gediend'. Zeer ongebruikelijk, maar gezien alle eerdere vertragingen begrijpelijk, moest het kortgeding zelfs gelasten dat de minister binnen twee weken een beslissing zou nemen op het gratieverzoek. ${ }^{7}$

Op 8 juli wees de minister het verzoek opnieuw af. Hoewel dat op basis van de jurisprudentie alleen kan op basis van informatie waar het gerechtshof in zijn advies nog geen rekening mee kon houden, laat de minister opnieuw de impact van het delict op de slachtoffers en de vergelding zwaarder wegen.

Ook in deze zaak is het interessant door de mensenrechtelijke en democratische bril van Sonja Snacken te kijken naar wat deze zaak zegt over het punitieve klimaat in Nederland. Aan de ene kant kan worden vastgesteld dat er opnieuw veelvuldig juridische middelen worden ingezet; dat de middelen uiteindelijk ook wel tot beweging leiden en dat er draagvlak voor is, in ieder geval onder juristen en (een deel van de) media. Anderzijds, dat met een ongekende volharding wordt vastgehouden aan politieke opvattingen die in strijd zijn met het recht en dat er zelfs geen middelen worden geschuwd om dat recht zijn normale (tijds)beloop te laten hebben. Die situatie is mijns inziens rechtstreeks in overeenstemming met de definitie van punitiviteit, die ik aan het begin van deze bijdrage citeerde en een democratische rechtstaat onwaardig.

6 RSJ 19 mei 2015, 14/3242/GV

7 Rechtbank den Haag 24 juni 2020, ECLI: NL RBDHA: 2020:5554 


\section{Referenties}

Bauman, Z. (2000). Liquid Modernity. Cambridge: Polity Press.

Beck, U. (1992). The risk society; toward a new modernity. London: Sage.

Boone, M. Er zitten hier alleen moslims. Een bijzondere afdeling voor 'terroristen': Mag? Werkt het? In: C. Brants \& S. van de Poel (red), Diverse kwesties. Liber amicorum prof. dr Frank Bovenkerk, BJU, Den Haag: 45-61.

Bovenkerk, F. (2011). De terroristenafdeling in Vught. Voor en tegen. In: Van der Leun et al (Eds.), De vogel vrij, Liber amicorum prof. dr. mr. Martin Moerings, BJU, Den Haag: 229-241.CPT, Report to the Authorities of the Kingdom of the Netherlands on the visits carried out to the Kingdom Europe, Aruba and the Netherlands Antilles, Strasbourg, February 2008.

Garland, D. (2001). The culture of control. Crime and social order in contemporary society. Chicago: University of Chicago Press.

Hudson, B. (2003). Justice in the risk society: Challenging and re-affirming justice in late modernity. London: Sage.

Pfaff, J.F. (2008). The empirics of prison growth: a critical review and path forward. Journal of Criminal Law \& Criminology, 98(2), 547-619.

RSJ (2006). Advies over de bijzondere opvang voor terroristen.

Snacken, S., Beyens, K. \& Tubex, H. (1995). Changing prison populations in western countries: Fate of policy? European Journal of Crime, Criminal Law and Criminal Justice, 3(1), 18-53.

Snacken, S. (2006). A reductionist Penal Policy and European Human Rights Standards. European Journal of Criminal Policy and Research, 12, 143-164.

Snacken. S. (2010). Resisting punitiveness in Europe. Theoretical Criminology, $14,273-292$.

Snacken, S. (2015). Punishment, legitimate policies and values: Penal moderation, dignity and human rights. Punishment \& Society, 17(3), 397-423.

Veldhuis, T.M. et al (2010). Terroristen in Detentie. Evaluatie van de Terroristenafdeling, Rijksuniversiteit Groningen, Faculteit Gedrags-en Maatschappijwetenschappen.

Von Hofer, H. (2003). Prison populations as political constructs: the case of Finland, Holland and Sweden. Journal of Scandinavian Studies in Criminology and Crime Prevention, 4(1), 21-38.

Young, J. (1999). The exclusive society: Social exclusion, crime, and difference in late modernity. London: Sage Publications. 